\title{
APORTE DE PALHA E NITROGÊNIO NO SISTEMA DE PRODUÇÃO DE SOJA NO OESTE PAULISTA
}

\author{
Luciana Boulhosa Fabris ${ }^{1}$, Juliano Carlos Calonego ${ }^{2}$, Carlos Henrique dos Santos ${ }^{1}$, Ana Carolina Monico \\ Moreira $^{1}$
}

${ }^{1}$ Universidade Estadual Paulista - UNOESTE, Programa de Pós-Graduação em Agronomia, Presidente Prudente, SP. Universidade Estadual Paulista - UNESP, Botucatu, SP. E-mail: lufabris@uol.com.br

\section{RESUMO}

Objetivou-se com este trabalho avaliar o efeito de sistemas de produção em semeadura direta com aporte diferenciado de palha e nitrogênio antecedendo ao cultivo da soja, visando aumento na produtividade desta leguminosa. $O$ experimento foi instalado e conduzido em área experimental da Faculdade de Ciências Agrárias da Universidade do Oeste Paulista - UNOESTE, em Presidente Prudente/SP, em um solo classificado como Argissolo Vermelho distroférrico entre janeiro de 2014 e abril de 2016. O delineamento experimental adotado foi em blocos casualizados, com quatro repetições, em esquema de parcelas subdivididas, sendo as parcelas constituídas por três rotações de culturas, I) Milho/Tremoço/Soja, II) Milho+Urochloa brizantha/Soja, III) Urochloa brizantha/Soja, e as subparcelas por quatro doses de $\mathrm{N}\left(50,100,150\right.$ e $200 \mathrm{~kg} \mathrm{ha}^{-1}$ ), aplicadas anualmente. Foram analisadas a quantidade de palha e sua persistência sobre o solo antes e após a semeadura da soja e a produtividade de soja nos dois anos do experimento. Os resultados foram submetidos à análise de variância e os efeitos das fontes de variação foram comparados pelo teste de Tukey ao nível de $5 \%$ de probabilidade. Os sistemas de produção influenciaram na quantidade de MS acumulada antes e após à semeadura da soja, nos dois anos avaliados. A relação $\mathrm{C} / \mathrm{N}$ foi influenciada pela interação $\mathrm{M}+\mathrm{U}$ na dose de 200 $\mathrm{kg} \mathrm{ha}^{-1}$ de $\mathrm{N}$ antes da semeadura da soja. A quantidade de matéria seca produzida pela interação entre a Urochloa com $200 \mathrm{~kg} \mathrm{ha}^{-1}$ de N, no momento da colheita da soja, evidenciaram que as rotações que utilizaram forrageiras produziram mais palha, e que a maior dose de $\mathrm{N}$ favoreceu positivamente a produtividade da forrageira e o maior aporte de $\mathrm{C}$ ao sistema. A adubação nitrogenada distribuída ao longo do ano agrícola tem potencial para aumentar a produtividade da soja, em anos sem restrição severa de água.

Palavras-chave: plantio direto; relação $\mathrm{C} / \mathrm{N}$; pastagem.

\section{CONTRIBUTION OF STRAW AND NITROGEN IN THE PRODUCTION SYSTEM WITH SOYBEAN IN THE WEST OF SÃO PAULO}

\begin{abstract}
The aim of this study was to evaluate the effect of no-tillage systems with different input of straw and nitrogen before soybean crop to increase soybean yield. A field experiment was carried out in an experimental area of the University of Western São Paulo, College of Agricultural Sciences, in Presidente Prudente/SP, in a dystroferric red-yellow Argisol, between January 2014 and April 2016. A randomized complete block design was followed with four replications in a split plot where the plots consisted of (I) Maize/Lupine/Soybean, II) Maize + Urochloa brizantha/Soybean, III) Urochloa brizantha/Soybean and in the subplots four nitrogen doses (50, 100, 150 and $200 \mathrm{~kg} \mathrm{ha}^{-1}$ ), applied annually. The amount of straw and its persistence on the soil before and after sowing of soybean and soybean yield in the two years of the experiment were analyzed. The results were submitted to analysis of variance and the effects of the variables were compared by Tukey test at the $5 \%$ probability level. The no-tillage systems influenced the amount of dry matter accumulated before and after soybean planting in the two evaluated years. The $\mathrm{C} / \mathrm{N}$ ratio was influenced by interaction between $\mathrm{M}+\mathrm{U}$ and $200 \mathrm{~kg} \mathrm{ha}^{-1}$ of $\mathrm{N}$ before soybean seeding. The amount of dry matter obtained by the interaction of Urochloa with $200 \mathrm{~kg} \mathrm{ha}^{-1}$ of $\mathrm{N}$ at the time of grain harvest, showed that the rotations that used forage produced more straw and that the supply of the highest nitrogen fertilizer dose favored the productivity of the forage and the greater contribution of $\mathrm{C}$ to the system. Nitrogen fertilization distributed throughout the agricultural year has the potential to increase soybean yield in years without severe water restriction.
\end{abstract}

Keywords: no-tillage; $\mathrm{C} / \mathrm{N}$ ratio; pasture. 


\section{INTRODUÇÃO}

A região do oeste paulista é considerada socioeconomicamente como uma das mais pobres do estado de São Paulo, sendo a atividade agropecuária a base da economia regional. $O$ solo de baixa fertilidade, a escassez de chuvas em grande parte do ano e a baixa retenção de água nos solos, devido aos reduzidos teores de matéria orgânica e argila, dificultam o cultivo tanto de lavouras como de pastagens, sendo comuns as baixas produções de grãos e forragens. Esse cenário, em muitos casos, desestimula os investimentos no meio rural, agravando ainda mais os problemas químicos e físicos dos solos, tornando-os cada vez menos produtivos.

A adoção de estratégias visando aumentar a produtividade desses solos é necessária, sendo recomendado o sistema de semeadura direta (SSD) e a integração lavoura-pecuária (ILP) (CHIODEROLI, 2010). O uso de plantas de cobertura com aptidão edafoclimática para a região, como é o caso das Urochloas (PEREIRA et al., 2011), e culturas graníferas com alto retorno financeiro podem ser uma estratégia para viabilizar a agricultura em áreas com predomínio de pecuária extensiva de baixa eficiência.

A soja é uma das mais importantes culturas na economia nacional e mundial, sendo seus grãos muito usados na produção de óleo vegetal, ração animal e em produtos alimentícios variados (COSTA NETO; ROSSI, 2000). Na safra 2017/2018 houve aumento de $3,2 \%$ na área cultivada com essa cultura saindo de $33.909,4$ mil hectares na safra 2016/2017 para atuais 34.991,4 mil hectares, demonstrando a importância deste grão para a economia nacional (CONAB, 2018).

Mesmo a cultura da soja não sendo recomendada para a região oeste do Estado de São Paulo, devido aos riscos do déficit hídrico, a chance de sucesso com a cultura pode aumentar com o aporte de matéria orgânica, com a conservação da água no perfil do solo e com as melhorias nas condições físicas, químicas e biológicas do solo, promovidas pelas forrageiras, que também produzirão palhada para o cultivo em sistema de semeadura direta (SILVA et al., 2011; FRANCHINI et al., 2011).

As Urochloas, na região Oeste do Estado de São Paulo são excelentes opções para a dupla função exigida das forrageiras, pois tem uma alta produção de fitomassa aérea e radicular, principalmente ao se beneficiar do efeito residual das adubações realizadas nas culturas graníferas, garantindo a cobertura do solo, a ciclagem de nutrientes, a retenção de água, entre outros benefícios. Porém, o aporte de matéria seca (MS) e, consequentemente, de carbono (C) por essa forrageira semi-perene dependerá, entre outros fatores, da fertilidade do solo e do esquema de rotação de cultura em que é inserida (GARCIA et al., 2012).

A realização de qualquer das modalidades de integração, consórcio, sucessão ou rotação, promovem benefícios ao sistema de produção, como o aumento de palhada para o SSD, menores custos de produção, aumento da fertilidade do solo, melhoria da ambiência para um maior conforto animal, além de maior eficiência da adubação devido ao efeito residual dos fertilizantes e ciclagem de nutrientes (KLUTHCOUSKI; AIDAR, 2003).

$O$ grande desafio em regiões de solos arenosos é a manutenção de cobertura do solo para garantir os resultados da atividade agrícola. Com isso, a adubação nitrogenada dos sistemas de produção, tende a promover o esperado auxílio nesta função, pois o balanço positivo de nitrogênio é essencial para evitar uma competição indesejada entre microrganismos e as plantas cultivadas, além de aumentar a produção de MS e o aporte de C pelas culturas (BODDEY et al., 2010; CONCEIÇÃO et al., 2013). Assim, rotações de culturas que privilegiam um maior aporte de $C$ demandarão maior fornecimento de $\mathrm{N}$, e, neste caso, o uso apenas da soja como fonte de $\mathrm{N}$ em sistemas de rotação envolvendo Urochloa, pode não suprir a demanda de $\mathrm{N}$ tanto pelas plantas como pela microbiota do solo. Portanto, o fornecimento de $\mathrm{N}$ via adubação verde ou mineral pode aumentar a produção das culturas e permitir o aumento do teor de matéria orgânica em sistemas com aporte de palhada de elevada relação $\mathrm{C} / \mathrm{N}$.

Objetivou-se com este trabalho avaliar o efeito de sistemas de produção em semeadura direta com aporte diferenciado de palha e nitrogênio antecedendo ao cultivo da soja, visando aumento na produtividade desta leguminosa.

\section{MATERIAL E MÉTODOS}

$O$ experimento foi instalado e conduzido em área experimental da Faculdade de Ciências Agrárias da Universidade do Oeste Paulista UNOESTE, em Presidente Prudente/SP, em um solo classificado como Argissolo Vermelho distroférrico, entre janeiro de 2014 e abril de 2016. A localização geográfica da área experimental é de latitude 22007 ' S, longitude 51응 $27^{\prime} \mathrm{W}$ e a altitude de $430 \mathrm{~m}$. O clima, segundo a classificação de Köppen, é do tipo Cwa, com temperatura média anual de $25 \circ \mathrm{C}$ e regime pluvial 
caracterizado por dois períodos distintos, um chuvoso de outubro a março e outro de baixo índice pluvial de abril a setembro.

A área experimental foi preparada mecanicamente em 2009, sendo desde então conduzida em sistema de semeadura direta, com a rotação de culturas envolvendo as culturas de milho/tremoço/sorgo. Antes de iniciar o experimento, em outubro de 2013, foram coletadas amostras de solo nas camadas de 0-10,
10-20 e 20-40 cm para caracterização das propriedades químicas e físicas (Tabelas 1 e 2). 0 experimento foi instalado em delineamento experimental com blocos casualizados, com quatro repetições, em esquema de parcelas subdivididas, sendo as parcelas constituídas por três rotações de culturas e as subparcelas por quatro doses de $\mathrm{N}$ aplicadas anualmente.

Tabela 1. Análise química de solo para caracterização da área nas profundidades 0-10, 10-20 e 20-40 cm

\begin{tabular}{|c|c|c|c|c|c|c|c|c|c|c|c|c|}
\hline \multirow{2}{*}{$\begin{array}{l}\text { Prof. } \\
(\mathrm{cm})\end{array}$} & \multirow{2}{*}{$\begin{array}{c}\mathrm{pH} \\
\left(\mathrm{CaCl}_{2}\right)\end{array}$} & \multirow{2}{*}{$\begin{array}{l}\text { M.O. } \\
\left(\mathrm{g} \mathrm{dm}^{-3}\right)\end{array}$} & & $\mathrm{S}-\mathrm{SO}_{4}{ }^{2-}$ & \multirow[t]{2}{*}{$\mathrm{Al}^{3+}$} & $\mathrm{H}+\mathrm{Al}$ & K & $\mathrm{Ca}$ & $\mathrm{Mg}$ & SB & \multirow[t]{2}{*}{ СTC } & \multirow{2}{*}{$\begin{array}{c}\mathrm{V} \\
(\%)\end{array}$} \\
\hline & & & \multicolumn{2}{|c|}{$-\left(\mathrm{mg} \mathrm{dm}^{-3}\right)-$} & & & Im & $\mathrm{OOl}_{\mathrm{c}} \mathrm{C}$ & & & & \\
\hline $0-10$ & 4,6 & 7 & 73 & 4 & 1 & 24 & 1,9 & 12 & 4 & 18 & 42 & 43 \\
\hline $10-20$ & 4,3 & 6 & 48 & 4 & 3 & 25 & 1,8 & 10 & 3 & 15 & 40 & 37 \\
\hline $20-40$ & 4,5 & 5 & 24 & 6 & 2 & 24 & 2,0 & 18 & 5 & 25 & 49 & 51 \\
\hline
\end{tabular}

Tabela 2. Análise granulométrica do solo antecedente à instalação do experimento, 2013.

\begin{tabular}{ccccc}
\hline $\begin{array}{c}\text { Profundidades } \\
(\mathrm{cm})\end{array}$ & Areia total & Silte & Argila & Classe Textural \\
\hline $0-10$ & 890 & 49 & 61 & \\
$10-20$ & 840 & 48 & 112 & Arenosa \\
$20-40$ & 833 & 67 & 100 & Arenosa \\
\hline
\end{tabular}

As rotações de culturas utilizadas nas parcelas experimentais foram: I) Milho/Tremoço/Soja, onde o milho e a soja foram cultivados para produção de grãos e o tremoço foi usado, após o milho e antes da soja, como adubo verde e cobertura do solo em SSD; II) Milho + Urochloa brizantha/Soja, onde o milho foi cultivado em consórcio com a Urochloa, mantendo-se a pastagem após a colheita do milho para produção de forragem e palhada; III) Urochloa brizantha/Soja, onde a gramínea foi cultivada solteira na maior parte do ano e a soja utilizada como única cultura granífera sobre a palhada da forrageira. Na Tabela 3 segue um esquema detalhado do histórico de cultivo de cada sistema nos anos de 2014 a 2016.

Tabela 3. Esquema de rotações de culturas que compuseram as parcelas experimentais entre os anos de 2014 e 2016 .

\begin{tabular}{|c|c|c|c|c|c|c|c|c|c|c|c|c|}
\hline & Jan & Fev & Mar & Abr & Mai & Jun & Jul & Ago & Set & Out & Nov & Dez \\
\hline \multicolumn{13}{|c|}{ Rotação 1} \\
\hline 2014 & $M$ & $M$ & $M$ & $M$ & $M$ & TRE & TRE & TRE & TRE & $\mathrm{S}$ & $S$ & $S$ \\
\hline 2015 & $S$ & $S$ & $S$ & $M$ & $M$ & $M$ & $M$ & TRE & TRE & TRE & $S$ & $S$ \\
\hline 2016 & $S$ & $S$ & $S$ & & & & & & & & & \\
\hline \multicolumn{13}{|c|}{ Rotação 2} \\
\hline 2014 & $M+B$ & $M+B$ & $M+B$ & $M+B$ & $M+B$ & $B$ & B & $B$ & B & $S$ & $S$ & $S$ \\
\hline 2015 & $S$ & $S$ & $S$ & $M+B$ & $M+B$ & $M+B$ & $M+B$ & B & B & B & $S$ & $S$ \\
\hline 2016 & S & $S$ & S & & & & & & & & & \\
\hline \multicolumn{13}{|c|}{ Rotação 3} \\
\hline 2014 & $B$ & $B$ & $B$ & $B$ & $B$ & $B$ & B & B & B & $S$ & $S$ & $S$ \\
\hline 2015 & $S$ & $S$ & $S$ & B & B & B & B & B & B & B & S & $S$ \\
\hline 2016 & $S$ & S & $S$ & & & & & & & & & \\
\hline
\end{tabular}


As doses de $\mathrm{N}$ utilizadas em subparcelas foram de 50, 100, 150 e $200 \mathrm{~kg} \mathrm{ha}^{-1}$, que foram aplicadas durante o cultivo das plantas nos anos de
2014/2015 e 2015/2016, de acordo com a Tabela 4.

Tabela 4. Cronograma de parcelamento das doses de $\mathrm{N}$ aplicadas durante o cultivo das espécies vegetais nos anos de 2014 e 2015.

\begin{tabular}{|c|c|c|c|c|}
\hline & \multicolumn{4}{|c|}{ Doses de $\mathrm{N}\left(\mathrm{kg} \mathrm{ha}^{-1}\right)$} \\
\hline & 50 & 100 & 150 & 200 \\
\hline & \multicolumn{4}{|c|}{ Rotação 1 (milho/tremoço/soja) } \\
\hline Semeadura do milho & 25 & 25 & 25 & 25 \\
\hline Milho com 4 folhas (V4) & 0 & 25 & 50 & 75 \\
\hline Milho com 8 folhas (V8) & 0 & 25 & 50 & 75 \\
\hline \multirow[t]{2}{*}{ Semeadura do tremoço } & 25 & 25 & 25 & 25 \\
\hline & \multicolumn{4}{|c|}{ Rotação 2 (milho+braquiária/braquiária/soja) } \\
\hline Semeadura do milho & 25 & 25 & 25 & 25 \\
\hline Milho com 4 folhas (V4) & 0 & 25 & 50 & 75 \\
\hline Milho com 8 folhas (V8) & 0 & 25 & 50 & 75 \\
\hline \multirow[t]{2}{*}{$\begin{array}{l}30 \text { dias antes da dessecação da } \\
\text { braquiária }\end{array}$} & 25 & 25 & 25 & 25 \\
\hline & \multicolumn{4}{|c|}{ Rotação 3 (braquiária/soja) } \\
\hline Semeadura da braquiária & 25 & 25 & 25 & 25 \\
\hline $\begin{array}{l}30 \text { dias após semeadura da } \\
\text { braquiária (DAS) }\end{array}$ & 0 & 25 & 50 & 75 \\
\hline 60 DAS & 0 & 25 & 50 & 75 \\
\hline $\begin{array}{l}30 \text { dias antes da dessecação da } \\
\text { braquiária }\end{array}$ & 25 & 25 & 25 & 25 \\
\hline
\end{tabular}

Onde: DAS = dias após semeadura; DAD = dias antes da dessecação da Urochloa

A instalação do experimento ocorreu em janeiro de 2014 com o manejo das seguintes culturas: milho híbrido AG 5055, tremoço branco, Urochloa brizantha (Syn. Brachiaria) cv. MG-5 e soja cultivar BMX Potencia RR. As parcelas experimentais foram demarcadas com 27 metros de comprimento e 6,3 metros de largura e as subparcelas com 6 metros de comprimento e 6,3 metros de largura, deixando $1 \mathrm{~m}$ de espaçamento entre as subparcelas dentro de cada parcela, $3 \mathrm{~m}$ entre as parcelas dentro de cada bloco e 5 metros entre os blocos.

A semeadura das espécies foi realizada mecanicamente, utilizando-se semeadora para plantio direto, equipada com disco de corte de palha. A adubação do milho e da Urochloa foram realizadas com $250 \mathrm{~kg} \mathrm{ha}^{-1}$ de 8-28-16 e da soja com $200 \mathrm{~kg} \mathrm{ha}^{-1}$ do fertilizante comercial 4-30-10, sendo que no tremoço não foi realizada adubação na semeadura.
O milho foi semeado no espaçamento entrelinhas de $0,90 \mathrm{~m}$ e com população de $60 \mathrm{mil}$ plantas por hectare. No consórcio entre Milho+Urochloa, a forrageira foi semeada em uma única linha, na entrelinha do milho (semeadura simultânea). Assim, como a Urochloa consorciada com o milho, a Urochloa solteira também foi semeada no espaçamento entrelinhas de $0,90 \mathrm{~m}$, utilizando $6,0 \mathrm{~kg} \mathrm{ha}^{-1}$ de sementes, considerando VC de 50\%. O tremoço foi semeado no espaçamento entrelinhas de $0,45 \mathrm{~m}$, utilizando 10 $\mathrm{kg} \mathrm{ha}^{-1}$ de sementes, e a soja também foi semeada no espaçamento entrelinhas de $0,45 \mathrm{~m}$, visando a obtenção de uma população de 300 mil plantas por hectare. As sementes de soja foram tratadas com $300 \mathrm{ml}$ do fungicida Vitavax - Thiram $200 \mathrm{SC}$ e $400 \mathrm{ml}$ do inseticida Cropstar, totalizando $700 \mathrm{ml}$ de solução/100 kg de sementes com adição de grafite. As sementes foram inoculadas com 0 produto Nodofix líquido, na dose de $100 \mathrm{ml} / 50 \mathrm{~kg}$ de sementes. 
As plantas de tremoço e Urochloa foram manejadas quimicamente por meio de dessecante de ação sistêmica, sendo a palhada mantida sobre solo até a semeadura da soja. O tremoço foi manejado antes da maturação fisiológica dos grãos e a Urochloa foi dessecada 30 dias antes da semeadura da soja. Os tratos culturais como controle de plantas daninhas, pragas e doenças foram realizados a partir de monitoramento periódico, e foram executados para que as espécies cultivadas apresentassem o máximo de desenvolvimento possível, dentro de critérios técnicos de uso de defensivos agrícolas e manejo cultural. As adubações com $\mathrm{P}_{2} \mathrm{O}_{5}$ e $\mathrm{K}_{2} \mathrm{O}$ foram realizadas de acordo recomendações de Raij et al. (1997).

Por ocasião da semeadura da soja e no estádio R7 de desenvolvimento foram coletadas amostras de palha depositadas sobre o solo, retirando-se três subamostras por unidade experimental com quadrado de madeira $(0,45 \mathrm{x}$ $0,45 \mathrm{~m}$ ) no espaçamento entre linhas da soja. 0 material vegetal foi seco em estufa de aeração forçada a $65{ }^{\circ} \mathrm{C}$, pesados em balanças com precisão de $0,01 \mathrm{~g}$ e os resultados convertidos em $\mathrm{kg} \mathrm{ha}^{-1}$.

Para estimar a produtividade de grãos foram colhidas manualmente, após a maturidade fisiológica dos grãos, as plantas contidas nas duas linhas centrais de cada unidade experimental, descartando 0,5 $\mathrm{m}$ de cada extremidade. Após esta operação, as plantas foram trilhadas e os grãos foram pesados e posteriormente calculou-se a produtividade de grãos, em kg ha ${ }^{-1}$, corrigida para o teor de água de $130 \mathrm{~g} \mathrm{~kg}^{-1}$.

Os resultados foram submetidos à análise de variância e os efeitos das variáveis foram comparados pelo teste de Tukey ao nível de $5 \%$ de probabilidade.

\section{RESULTADOS E DISCUSSÃO}

Os sistemas avaliados influenciaram na quantidade de matéria seca (MS), $\mathrm{N}$ e relação $\mathrm{C} / \mathrm{N}$ no primeiro ano de avaliação, com interação entre sistemas de produção e doses de $\mathrm{N}$ significativa para a relação $\mathrm{C} / \mathrm{N}$ (Tabela 5). No segundo ano avaliado somente os sistemas influenciaram na quantidade de MS acumulada (Tabela 5).

Tabela 5. Valores de $\mathrm{F}$ calculados pela análise de variância para a matéria seca (MS), teores de nitrogênio (N), carbono (C) e relação $\mathrm{C} / \mathrm{N}$ na palha antes da semeadura da soja (início), em função dos sistemas de produção e doses de N, em 2014-2015 e 2015-2016

\begin{tabular}{cccc}
\hline Causas de variação & $\mathrm{MS}$ & $\mathrm{N}$ & $\mathrm{C} / \mathrm{N}$ \\
\cline { 2 - 4 } & $2014-2015$ (início) & \\
\hline Sistemas (S) & $33,6^{* *}$ & $106,2^{* *}$ & $32,6^{* *}$ \\
Doses de N (D) & $1,1 \mathrm{~ns}$ & $0,5 \mathrm{~ns}$ & $0,8 \mathrm{~ns}$ \\
S X D & $0,7 \mathrm{~ns}$ & $2,3 \mathrm{~ns}$ & $2,8^{*}$ \\
CV (\%) & 35,1 & 16,3 & 24,7 \\
CV (\%) & 36,4 & 10,1 & 14,4 \\
\hline & $2015-2016$ & $3,8 \mathrm{~ns}$ & $3,1 \mathrm{~ns}$ \\
\hline Sistemas (S) & $5,9^{*}$ & $1,46 \mathrm{~ns}$ & $1,8 \mathrm{~ns}$ \\
Doses de N (D) & $0,1 \mathrm{~ns}$ & $0,9 \mathrm{~ns}$ & $1,5 \mathrm{~ns}$ \\
S x D & $1,7 \mathrm{~ns}$ & 33,8 & 26,9 \\
CV (\%) & 42,1 & 30,7 & 22,2 \\
CV (\%) & 36,7 & d
\end{tabular}

ns $, *, * *$, não significativo, significativo a $5 \%$ e a $1 \%$ de probabilidade pelo teste $\mathrm{F}$, respectivamente.

No primeiro ano avaliado, as melhores médias para MS e para os teores de $\mathrm{N}$ foram encontradas para o sistema com tremoço, ou seja, $2.906 \mathrm{~kg} \mathrm{ha}^{-1}$ e $26,7 \mathrm{~g} \mathrm{~kg}^{-1}$, respectivamente (Tabela 6). Neste ano, não foi possível colher o milho nas duas primeiras rotações avaliadas, permanecendo nas parcelas grande quantidade de restos culturais, que são mais pesados que as gramíneas utilizadas nas demais rotações. Assim, houve o fornecimento de resíduos mais pesados para o sistema Tremoço, mas que não tem a mesma eficiência de cobertura de solo e nem a mesma relação $\mathrm{C} / \mathrm{N}$ que nos sistemas que utilizam Urochloa, tanto que no segundo ano avaliado, onde o milho foi colhido na época correta, permaneceu no solo apenas os restos culturais do tremoço, e a maior quantidade de palha foi adicionada ao solo pelo sistema Urochloa não diferindo do sistema Urochloa + milho. 
Tabela 6. Resultados da análise de variância da palhada antes da semeadurada soja (início) para os parâmetros quantidade de matéria seca $(\mathrm{MS})$, teores de nitrogênio $(\mathrm{N})$ ), carbono $(\mathrm{C})$ e relação $\mathrm{C} / \mathrm{N}$, em função das variáveis sistemas de produção e doses de nitrogênio, nos anos agrícolas 2014-2015 e 2015-2016.

\begin{tabular}{|c|c|c|c|}
\hline \multirow{3}{*}{ Sistemas ${ }^{(2)}$} & \multicolumn{3}{|c|}{2014 - 2015 (início) } \\
\hline & MS & $\mathrm{N}$ & $\mathrm{C} / \mathrm{N}$ \\
\hline & $\mathrm{kg} \mathrm{ha}^{-1}$ & $\mathrm{~g} \mathrm{~kg}^{-1}$ & \\
\hline Tremoço & $2.906 \mathrm{a}$ & $26,7 \mathrm{a}$ & $16 \mathrm{~b}$ \\
\hline$M+U$ & $1.307 \mathrm{~b}$ & $13,9 \mathrm{~b}$ & $32 \mathrm{a}$ \\
\hline Urochloa & $1.274 b$ & $13,2 b$ & $33 \mathrm{a}$ \\
\hline \multicolumn{4}{|l|}{ Doses de $\mathrm{N}^{(1)}$} \\
\hline 50 & $1.691 \mathrm{a}$ & $17,8 \mathrm{a}$ & $27 \mathrm{a}$ \\
\hline 100 & $1.728 \mathrm{a}$ & $17,6 \mathrm{a}$ & $27 \mathrm{a}$ \\
\hline 150 & $2.137 a$ & 18,4 a & $25 a$ \\
\hline 200 & $1.761 \mathrm{a}$ & $18,1 \mathrm{a}$ & $27 \mathrm{a}$ \\
\hline \multicolumn{4}{|c|}{$2015-2016$} \\
\hline Tremoço & $1.268 \mathrm{~b}$ & $14,3 \mathrm{a}$ & $33 \mathrm{a}$ \\
\hline$M+U$ & $1.590 \mathrm{ab}$ & $11,0 \mathrm{a}$ & $40 a$ \\
\hline Urochloa & $2.109 a$ & $10,7 \mathrm{a}$ & $41 \mathrm{a}$ \\
\hline \multicolumn{4}{|l|}{ Doses de $\mathrm{N}^{(1)}$} \\
\hline 50 & $1.654 \mathrm{a}$ & $12,1 \mathrm{a}$ & $37 \mathrm{a}$ \\
\hline 100 & $1.628 \mathrm{a}$ & $13,4 \mathrm{a}$ & $35 \mathrm{a}$ \\
\hline 150 & $1.723 \mathrm{a}$ & $12,2 \mathrm{a}$ & $37 a$ \\
\hline 200 & $1.618 \mathrm{a}$ & $10,3 \mathrm{a}$ & $43 \mathrm{a}$ \\
\hline
\end{tabular}

(1) Doses de $\mathrm{N} \mathrm{em} \mathrm{kg} \mathrm{ha}{ }^{-1}$, aplicadas parceladamente ao longo do ano agrícola. ${ }^{(2)}$ Sistemas de Produção envolvendo diferentes espécies para produção de palha. As médias seguidas pela mesma letra na coluna não diferem estatisticamente entre si pelo teste de Tukey ao nível de $5 \%$ de probabilidade.

Apesar de no primeiro ano avaliado ter sido obtida maior quantidade de palha nas parcelas que utilizaram o tremoço, as melhores relações $\mathrm{C} / \mathrm{N}$ estão presentes nos sistemas $\mathrm{M}+\mathrm{U}$ e $\mathrm{U}$ (Tabela 6) confirmando que os sistemas que integram gramíneas como a Urochloa fornecem maior quantidade de $\mathrm{C}$ para o sistema. $\mathrm{Na}$ interação entre sistemas de produção e doses de $\mathrm{N}$, a melhor média ocorreu para a interação $\mathrm{M}+\mathrm{U}$ com $200 \mathrm{~kg} \mathrm{ha}^{-1}$ de $\mathrm{N}$, com uma relação $\mathrm{C} / \mathrm{N}$ de 37 (Tabela 7), demonstrando que a maior quantidade de $\mathrm{N}$ ofertada ao sistema favoreceu a produtividade da forrageira que promoveu a cobertura de solo mais eficiente beneficiando a cultura subsequente.

No segundo ano agrícola, somente os sistemas influenciaram na produção de MS (Tabela $5)$, encontrando-se a melhor média (2.109 $\left.\mathrm{kg} \mathrm{ha}^{-1}\right)$ no sistema que utilizou Urochloa solteira, demonstrando a maior capacidade das forrageiras, especialmente a Urochloa, em produzir MS para cobertura de solos nos sistemas de produção (KLUTHCOUSKI et al., 2003; AIDAR; KLUTHCOUSKI, 2003; CRUSCIOL; BORGHI, 2007; GARCIA, 2010).

Tabela 7. Desdobramento da interação entre os fatores doses de $\mathrm{N}$ e sistemas de produção para os resultados de relação C/N da palhada na semeadura da soja, 2014-2015.

\begin{tabular}{|c|c|c|c|}
\hline \multirow{3}{*}{ Doses de $\mathrm{N}^{(1)}$} & \multicolumn{3}{|c|}{ Sistemas de Produção ${ }^{(2)}$} \\
\hline & TRE & $\mathrm{M}+\mathrm{U}$ & $U$ \\
\hline & \multicolumn{3}{|l|}{$\mathrm{C} / \mathrm{N}$} \\
\hline 50 & $15 \mathrm{~b} \mathrm{~A}$ & 33 a $A B$ & 34 a $A$ \\
\hline 100 & $16 \mathrm{~b} \mathrm{~A}$ & 31 a $A B$ & 34 a $A$ \\
\hline 150 & $16 \mathrm{~b} \mathrm{~A}$ & 27 a B & 33 a $A$ \\
\hline 200 & $15 \mathrm{c} \mathrm{A}$ & 37 a $A$ & $29 \mathrm{~b} \mathrm{~A}$ \\
\hline
\end{tabular}

(1) Doses de $\mathrm{N} \mathrm{em} \mathrm{kg} \mathrm{ha}{ }^{-1}$ aplicadas parceladamente ao longo do ano agrícola. ${ }^{(2)}$ Sistemas de Produção envolvendo diferentes espécies para produção de palha; TRE = milho/tremoço; $\mathrm{M}+\mathrm{U}=$ milho + Urochloa; $\mathrm{U}=$ Urochloa . As médias seguidas pela mesma letra maiúscula na coluna e minúscula na linha não diferem estatisticamente entre si pelo teste de Tukey ao nível de $5 \%$ de probabilidade. 
Os sistemas de produção e suas interações com as doses de $\mathrm{N}$ influenciaram o acúmulo de MS no solo, na coleta antecedente à colheita da soja, nos dois anos de avaliação (Tabela 8).

Tabela 8. Valores de $\mathrm{F}$ calculados pela análise de variância para os parâmetros quantidade de matéria seca $(\mathrm{MS})$, nitrogênio $(\mathrm{N})$, carbono $(\mathrm{C})$ e relação $\mathrm{C} / \mathrm{N}$, da palha da soja antes da colheita (final), em função dos sistemas de produção e doses de N, em 2014-2015 e 2015-2016.

\begin{tabular}{cccc}
\hline \multirow{2}{*}{ Causas de variação } & MS & $\mathrm{N}$ & $\mathrm{C} / \mathrm{N}$ \\
\cline { 2 - 4 } & & $2014-2015$ (final) & \\
\hline Sistemas (S) & $16,2^{* *}$ & $2,3 \mathrm{~ns}$ & $1,3 \mathrm{~ns}$ \\
Doses de N (D) & $2,6 \mathrm{~ns}$ & $0,7 \mathrm{~ns}$ & $0,4 \mathrm{~ns}$ \\
S x D & $3,0^{*}$ & $1,5 \mathrm{~ns}$ & $1,2 \mathrm{~ns}$ \\
CV (\%) & 44,1 & 24,8 & 23,8 \\
CV (\%) & 30,1 & 24,0 & 20,9 \\
\hline & $2015-2016$ & & $0,3 \mathrm{~ns}$ \\
\hline Sistemas (S) & $34,1^{* *}$ & $0,1 \mathrm{~ns}$ & $1,3 \mathrm{~ns}$ \\
Doses de N (D) & $1,4 \mathrm{~ns}$ & $1,8 \mathrm{~ns}$ & $1,5 \mathrm{~ns}$ \\
S X D & $12,6^{* *}$ & $2,4 \mathrm{~ns}$ & 28,0 \\
CV (\%) & 23,7 & 29,5 & 30,7 \\
CV (\%) & 38,7 & 26,3 &
\end{tabular}

ns $, *, * *$, não significativo, significativo a $5 \%$ e a $1 \%$ de probabilidade pelo teste $F$, respectivamente.

Dentre os sistemas, aqueles que utilizaram a Urochloa foram superiores em acúmulo de MS (Tabela 9) evidenciando que as plantas forrageiras tem maior capacidade de permanência no solo por apresentarem maior relação $\mathrm{C} / \mathrm{N}$ (Tabela 9), garantindo os benefícios da cobertura do solo por mais tempo.

Tabela 9. Resultados da análise de variância dos parâmetros quantidade de matéria seca (MS), nitrogênio (N), carbono (C) e relação $\mathrm{C} / \mathrm{N}$ na palha de soja antes da colheita (final), em função dos sistemas de produção e das doses de N, em 2014-2015 e 2015-2016.

\begin{tabular}{|c|c|c|c|}
\hline \multirow[b]{2}{*}{ Sistemas ${ }^{(2)}$} & \multicolumn{3}{|c|}{2014 - 2015 (final) } \\
\hline & $\begin{array}{c}\mathrm{MS} \\
\left(\mathrm{kg} \mathrm{ha}^{-1}\right)\end{array}$ & $\begin{array}{c}\mathrm{N} \\
\left(\mathrm{g} \mathrm{kg}^{-1}\right)\end{array}$ & $\mathrm{C} / \mathrm{N}$ \\
\hline Tremoço & $953 \mathrm{~b}$ & $18,1 \mathrm{a}$ & $25 a$ \\
\hline$M+U$ & $2.554 \mathrm{a}$ & $15,4 \mathrm{a}$ & $28 a$ \\
\hline Urochloa & $2.313 \mathrm{a}$ & $15,4 \mathrm{a}$ & $28 a$ \\
\hline \multicolumn{4}{|l|}{ Doses de $\mathrm{N}^{(1)}$} \\
\hline 50 & $1.691 \mathrm{a}$ & $17,8 \mathrm{a}$ & $26 a$ \\
\hline 100 & $1.890 \mathrm{a}$ & $15,8 \mathrm{a}$ & $28 a$ \\
\hline 150 & 1.849 a & $16,8 \mathrm{a}$ & $27 a$ \\
\hline 200 & $2.330 \mathrm{a}$ & $15,6 \mathrm{a}$ & $28 a$ \\
\hline \multicolumn{4}{|c|}{$2015-2016$} \\
\hline Tremoço & $576 c$ & $10,6 \mathrm{a}$ & $44 \mathrm{a}$ \\
\hline$M+U$ & 1.199 a & $10,9 \mathrm{a}$ & $41 \mathrm{a}$ \\
\hline Urochloa & $927 \mathrm{~b}$ & $10,5 \mathrm{a}$ & $45 a$ \\
\hline \multicolumn{4}{|l|}{ Doses de $\mathrm{N}^{(1)}$} \\
\hline 50 & $978 \mathrm{a}$ & $12,0 \mathrm{a}$ & $37 a$ \\
\hline 100 & $964 \mathrm{a}$ & $10,9 \mathrm{a}$ & $43 a$ \\
\hline 150 & $722 a$ & $10,3 \mathrm{a}$ & $47 a$ \\
\hline 200 & $940 \mathrm{a}$ & $9,4 \mathrm{a}$ & $46 a$ \\
\hline
\end{tabular}

(1) Doses de $\mathrm{N} \mathrm{em} \mathrm{kg} \mathrm{ha}{ }^{-1}$, aplicadas parceladamente ao longo do ano agrícola. ${ }^{(2)}$ Sistemas de Produção envolvendo diferentes espécies para produção de palha. As médias seguidas pela mesma letra na coluna não diferem estatisticamente entre si pelo teste de Tukey ao nível de $5 \%$ de probabilidade.

As interações influenciaram na produção de MS, cuja maior média $\left(3.548 \mathrm{~kg} \mathrm{ha}^{-1}\right)$ foi obtida entre o sistema Urochloa e a dose de $200 \mathrm{~kg} \mathrm{ha}^{-1}$ de $\mathrm{N}$, no ano agrícola de 2014-2015. No 
ano seguinte, o maior acúmulo de MS (1.937 kg ha-

$\left.{ }^{1}\right)$ ocorreu no sistema $M+U$ com a adubação de 100

$\mathrm{kg} \mathrm{ha}^{-1}$ de N (Tabela 10).

Tabela 10. Desdobramento da interação entre os fatores doses de $\mathrm{N}$ e sistemas de produção para os

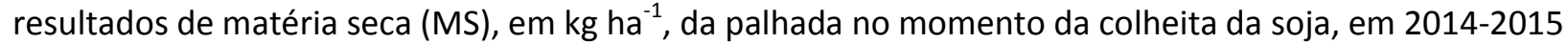

\begin{tabular}{|c|c|c|c|}
\hline \multirow{3}{*}{ Doses de $\mathrm{N}^{(1)}$} & \multicolumn{3}{|c|}{ Sistemas de Produção(2) } \\
\hline & TRE & $\mathrm{M}+\mathrm{U}$ & U \\
\hline & \multicolumn{3}{|c|}{$2014-2015$} \\
\hline 50 & 671 b A & 2.472 a $A$ & 1.929 a B \\
\hline 100 & 1.016 b A & 2.643 a $A$ & $2.012 a b B$ \\
\hline 150 & 1.190 b A & 2.594 a A & $1.764 a b B$ \\
\hline \multirow[t]{2}{*}{200} & 935 c A & $2.508 \mathrm{~b} \mathrm{~A}$ & 3.548 a A \\
\hline & \multicolumn{3}{|c|}{$2015-2016$} \\
\hline 50 & 205 b B & $1.184 \mathrm{a} \mathrm{B}$ & 1.544 a A \\
\hline 100 & 703 b AB & 1.937 a A & 251 b C \\
\hline 150 & 1.004 a $A B$ & 430 a $C$ & 732 a BC \\
\hline 200 & 392 b A & 1.246 a B & 1.180 a $A B$ \\
\hline
\end{tabular}

(1) Doses de $\mathrm{N}$ em kg ha ${ }^{-1}$ aplicadas parceladamente ao longo do ano agrícola. ${ }^{\text {(2) }}$ Sistemas de Produção envolvendo diferentes espécies para produção de palha; $\mathrm{TRE}=$ milho/tremoço; $\mathrm{M}+\mathrm{B}=$ milho + Urochloa; $\mathrm{B}=$ Urochloa . As médias seguidas pela mesma letra maiúscula na coluna e minúscula na linha não diferem estatisticamente entre si pelo teste de Tukey ao nível de $5 \%$ de probabilidade.

As doses de $\mathrm{N}$ interferiram significativamente na produtividade da soja, na safra 2014-2015 (Tabela 11). A maior média (4.137 $\mathrm{kg} \mathrm{ha}^{-1}$ ) foi obtida com a introdução de $200 \mathrm{~kg} \mathrm{ha}^{-1}$ de $\mathrm{N}$, indicando que a adubação nitrogenada no sistema de produção auxiliou no metabolismo dos microrganismos relacionados à decomposição de palhada e na nodulação de soja, favorecendo a maior produtividade. Balbinot Júnior et al. (2014), ao testarem doses $\mathrm{N}$ no manejo da cultura da soja em solos arenosos, não obtiveram resultados significativos, indicando que o melhor aproveitamento deste nutriente para este tipo de solo ocorre com a adubação do sistema de produção, onde as perdas são menores.

Tabela 11. Valores de F calculados pela análise de variância para análise de produtividade da safra de soja, nos anos agrícolas 2014-2015 e 2015-2016, em função das variáveis sistemas de produção e doses de nitrogênio.

\begin{tabular}{cc}
\hline Causas de Variação & Produtividade \\
\hline Ano 2014-2015 \\
\hline Sistemas (S) & $1,5 \mathrm{~ns}$ \\
Doses de N (D) & $3,6^{*}$ \\
S x D & $2,3 \mathrm{~ns}$ \\
CV \% & 13,9 \\
CV \% & 9,4 \\
\hline \multicolumn{1}{c}{ Ano 2015 - 2016 } \\
\hline Sistemas (S) \\
Doses de N (D) \\
S x D & $0,2 \mathrm{~ns}$ \\
CV \% & $1,8 \mathrm{~ns}$ \\
CV \% & $0,2 \mathrm{~ns}$ \\
\end{tabular}

ns,$* * *$, não significativo, significativo a $5 \%$ e a $1 \%$ de probabilidade pelo teste $\mathrm{F}$, respectivamente.

A média de produtividade de soja no primeiro ano de manejo foi de $3.873 \mathrm{~kg} \mathrm{ha}^{-1}$ (Tabela 12), demonstrando o potencial produtivo na região quando utilizados sistemas conservacionistas. Franchini et al. (2016) obtiveram maior produtividade de soja cultivada em sucessão às Urochloas brizantha e ruziziensis, em solos arenosos, diante da grande capacidade de enraizamento destas gramíneas, que possibilitaram maior crescimento das raízes de soja, o que refletiu positivamente na produtividade de grãos da oleaginosa. Na Tabela 
12, verifica-se que, mesmo não havendo influencia significativa dos sistemas na produtividade, o maior incremento na produção de soja ocorreu no sistema de manejo com a Urochloa solteira, provavelmente em razão da menor competição por nutrientes.

Tabela 12. Produtividade da safra de soja, em kg ha ${ }^{-1}$, nos anos agrícolas 2014-2015 e 2015-2016, em função dos sistemas de produção e das doses de N.

\begin{tabular}{|c|c|}
\hline Sistemas ${ }^{(2)}$ & $\begin{array}{l}\text { Produtividade } \\
\qquad\left(\mathrm{kg} \mathrm{ha}^{-1}\right)\end{array}$ \\
\hline \multicolumn{2}{|c|}{$2014-2015$} \\
\hline Tremoço & $3.733 a$ \\
\hline$M+U$ & $3.836 \mathrm{a}$ \\
\hline Urochloa & $4.051 \mathrm{a}$ \\
\hline \multicolumn{2}{|l|}{ Doses de $\mathrm{N}^{(1)}$} \\
\hline 50 & $3.683 b$ \\
\hline 100 & $3.759 a b$ \\
\hline 150 & $3.915 a b$ \\
\hline 200 & $4.137 \mathrm{a}$ \\
\hline \multicolumn{2}{|c|}{$2015-2016$} \\
\hline Tremoço & $1.477 \mathrm{a}$ \\
\hline$M+U$ & $1.455 \mathrm{a}$ \\
\hline Urochloa & $1.367 \mathrm{a}$ \\
\hline \multicolumn{2}{|l|}{ Doses de $\mathrm{N}^{(1)}$} \\
\hline 50 & $1.693 \mathrm{a}$ \\
\hline 100 & $1.331 \mathrm{a}$ \\
\hline 150 & $1.316 \mathrm{a}$ \\
\hline 200 & $1.392 \mathrm{a}$ \\
\hline
\end{tabular}

(1) Doses de $\mathrm{N}$ em $\mathrm{kg} \mathrm{ha}^{-1}$, aplicadas parceladamente ao longo do ano agrícola. ${ }^{\text {(2) }}$ Sistemas de Produção envolvendo diferentes espécies para produção de palha. As médias seguidas pela mesma letra na coluna não diferem estatisticamente entre si pelo teste de Tukey ao nível de $5 \%$ de probabilidade.

No segundo ano de avaliação, houve redução na produtividade da soja em razão da ocorrência de um veranico em janeiro de 2016, coincidindo com a época de enchimento dos grãos. Este fato evidenciou o risco da interferência da má distribuição das chuvas de verão na região oeste do Estado de São Paulo na produtividade das lavouras. Franchini et al. (2016) descreveram que o déficit hídrico afeta a produtividade da soja por comprometer o estabelecimento da cultura, a floração e o enchimento de grãos.

Embora os sistemas de produção não tenham influenciado significativamente na produtividade da soja, os sistemas que utilizaram forrageiras na rotação das culturas apresentaram média superior ao sistema que utilizou o tremoço, indicando que as forrageiras são capazes de promover melhor equilíbrio no manejo do sistema de produção favorecendo a produtividade da cultura principal.

\section{CONCLUSÕES}

Os sistemas de produção influenciaram na quantidade de MS acumulada antes e após à semeadura da soja, nos dois anos avaliados.

A quantidade de matéria seca produzida pela interação entre a Urochloa com $200 \mathrm{~kg} \mathrm{ha}^{-1}$ de $\mathrm{N}$, no momento da colheita da soja, evidenciaram que as rotações que utilizaram forrageiras produziram mais palha, e que a maior dose de $\mathrm{N}$ favoreceu a produtividade da forrageira e o maior aporte de $\mathrm{C}$ ao sistema.

A adubação nitrogenada distribuída ao longo do ano agrícola tem potencial para aumentar a produtividade da soja, em anos sem restrição severa de água.

\section{REFERÊNCIAS}

AIDAR, H.; KLUTHCOUSKI, J. Evolução das atividades lavoureira e pecuária nos Cerrados. In: KLUTHCOUSKI, J.; STONE, L.F.; AIDAR, H. (Ed.). Integração lavoura-pecuária. Santo Antônio de Goiás: Embrapa Arroz e Feijão, 2003. p. 25-58. 
BALBINOT JUNIOR, A. A.; REIS, R. F.; DEBIASI, H.; FRANCHINI, J. C.; MANDARINO, J. M. G.; FERREIRA, A. S.; WERNER, F.; IWASAKI, G. S. Adubação nitrogenada na soja cultivada em solo arenoso no sistema de integração lavoura-pecuária. In: REUNIÃO DE PESQUISA DE SOJA DA REGIÃO CENTRAL DO BRASIL, 34., 2014, Londrina. Resumos expandidos... Brasília, DF: Embrapa, 2014. p. 4041.

BODDEY, R.M.; JANTALIA, C.P.; CONCEIÇÃO, P.C.; ZANATTA, J.A.; BAYER, C.; MIELNIZUK, J.; DIECKOW, J.; SANTOS, H.P.; DENARDIN, J.E.; AITA, C.; GIACOMINI, S.J.; ALVES, B.J.R.; URQUIAGA, S. Carbon accumulation at depth in Ferralsols under zero till subtropical agriculture. Global Change Biology, v. 16, p. 784-795, 2010. https://doi.org/10.1111/j.1365-

2486.2009.02020.x

CHIODEROLI, C. A.; MELO, L. M. M. de; GRIGOLLI, P. J.; SILVA, J. O. da R.; CESARIN, A. L. Consorciação de braquiárias com milho outonal em plantio direto sob pivô central. Revista Brasileira de Engenharia Agrícola, v. 30, n. 6, p. 1101-1109, $2010 . \quad$ http://dx.doi.org/10.1590/S010069162010000600011

CONAB. Acompanhamento da Safra Brasileira de Grãos. v. 5 - Safra 2017/18 - n. 4 - Quarto Levantamento. Disponível em: http://www.conab.gov.br/OlalaCMS/uploads/arqu ivos/18_01_11_14_17_49_graos_4o_levantament o.pdf. Acesso em: 18 jan. 2018.

CONCEIÇÃO, P.C.; DIECKOW, J; BAYER, C. Combined role of no-tillage and cropping systems in soil carbon stocks and stabilization. Soil and Tillage Research, v. 129, p. 40 - 47, 2013. http://dx.doi.org/10.1016/j.still.2013.01.006

COSTA NETO, P. R.; ROSSI, L. F. S. Produção de biocombustível alternativo ao óleo diesel através da transesterificação de óleo de soja usado em fritura. Química Nova, v. 23, n. 4, p. 531-537, $2000 . \quad$ http://dx.doi.org/10.1590/S010040422000000400017

CRUSCIOL, C. A. C.; BORGHI, E. Consórcio de milho com braquiária: produção de forragem e palhada para o plantio direto. Revista Plantio Direto, v. 100, p. 10-14, 2007.

FRANCHINI, J. C.; BALBINOT JR., A. A.; DEBIASI, H.; COSTA, J. M.; SICHIERI, F. R.; TEIXEIRA, L. C. Soja em solos arenosos: papel do Sistema Plantio
Direto e da Integração Lavoura-Pecuária. Embrapa: Brasília, 2016. (Circular Técnica, 116).

FRANCHINI, J. C.; COSTA, J. M. da; DEBIASI, H.; TORRES, E. Importância da rotação de culturas para a produção agrícola sustentável no Paraná. Londrina: Embrapa Soja, 2011. 52p. (Documentos / Embrapa Soja, n.327)

GARCIA, C. M. de P.; ANDREOTTI, M.; TARSITANO, M. A. A.; TEIXEIRA FILHO, M. C. M.; LIMA, A. E. da S.; BUZETTI, S. Análise econômica da produtividade de grãos de milho consorciado com forrageiras dos gêneros Brachiaria e Panicum em sistema plantio direto. Revista Ceres, v. 59, n. 2, p. 157-163, 2012. http://dx.doi.org/10.1590/S0034737X2012000200002

GARCIA, R. A. Rotação de Culturas e Propriedades Físicas e Matéria Orgânica de um Latossolo. 2010. 146 f. Tese (Doutorado) - Faculdade de Ciências Agronômicas, Universidade Estadual Paulista, Botucatu, 2010.

IBGE. Instituto brasileiro de geografia e estatística. Canais: Cidades@. 2010. Disponível em: <http://www.ibge.gov.br/cidadesat/painel/painel. php?codmun=354140 . Acesso em: 8 jan. 2014.

KLUTHCOUSKI, J.; AIDAR, H. Implantação, condução e resultados obtidos com o sistema Santa Fé. In: KLUTHCOUSKI, J.; STONE, L.F.; AIDAR, H. (Ed.). Integração lavoura-pecuária. Santo Antônio de Goiás: Embrapa Arroz e Feijão, 2003. p. 407-442.

KLUTHCOUSKI, J.; COBUCCI, T.; AIDAR, H., COSTA, J. L. S.; PORTELA, C. Cultivo do feijoeiro em palhada de braquiária. Santo Antônio de Goiás: Embrapa Arroz e Feijão, 2003. 28p. (Documentos / Embrapa Arroz e Feijão).

PEREIRA, R. A.; ALVES, P. L. da C. A.; CORRÊA, M. P.; DIAS, T. C. S. Influência da cobertura de aveiapreta e milheto sobre comunidade de plantas daninhas e produção de soja. Revista Brasileira de Ciências Agrárias, v. 6, n. 1, p. 1-10, 2011. https://doi.org/10.5039/agraria.v6i1a545

RAIJ, B. VAN; CANTARELLA, H.; QUAGGIO, J.A.; FURLANI, A.M.C. Recomendações de adubação e calagem para o Estado de São Paulo. Campinas: Instituto Agronômico, 1997. 285p. (Boletim técnico, n. 100). 
SILVA, D. A.; SOUZA, L. C. F. de; VITORINO, A. C. T.; GONÇALVES, M. C. Aporte de fitomassa pelas sucessões de culturas e sua influência em atributos físicos do solo no sistema plantio direto. Bragantia, v. 70, n. 1, p. 147-156, 2011. http://dx.doi.org/10.1590/S0006-

$\underline{87052011000100021}$

Recebido para publicação em 29/03/2018

Revisado em 03/07/2018

Aceito em 10/07/2018 